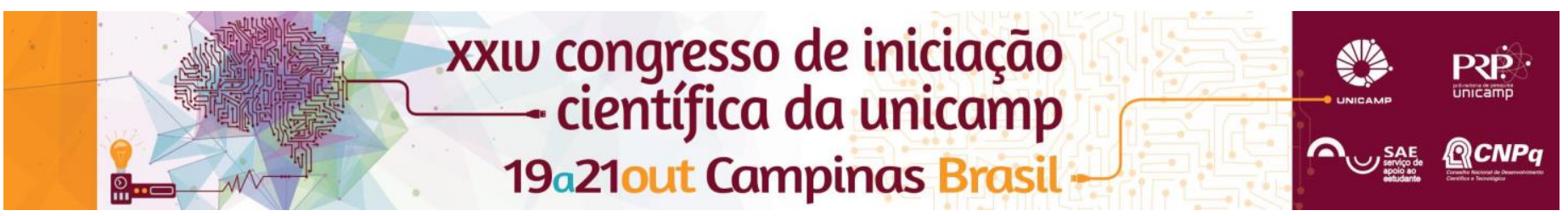

\title{
Creating an app to robotic control in educational environment
}

\section{Leonardo S. de Almeida*, Conrado L. Silva, João V. V. D'Abreu.}

\begin{abstract}
There isn't nothing more common to people than a mobile phone. Then, the presence of this devices in robotic is atractive to kids and laypeople. Aiming this, we crafted a platform to control robotic devices by bluetooth and a simple app for smartphones, using MIT App Inventor, to command this platform.
\end{abstract}

\section{Key words:}

Mobile app, MIT App Inventor, Robotic.

\section{Introduction}

In the last year, we developed a device able to control robots by bluetooth comunication with a cellphone, but we didn't have an own app to send this comand. Now, using the MIT App Inventor[1] (an online software to make applications to Android OS), we are crafting an app than send comands to this platform, controling the robot which is conected to that. Together, the app and the platform will be used in schools, within another projects of Educational Robotics.

\section{Results and Discussion}

We chose the MIT App Inventor because it's a free (and easy) way to develop apps. This method have a few points in which could be better, but is enough for our purpose. The software interface is separated in two: the "Design" and "Block" tabs. In the first one, shown in image 1, we make the visual of the application, the screen, than has to be the most intuitive than possible because will be used by childrens.

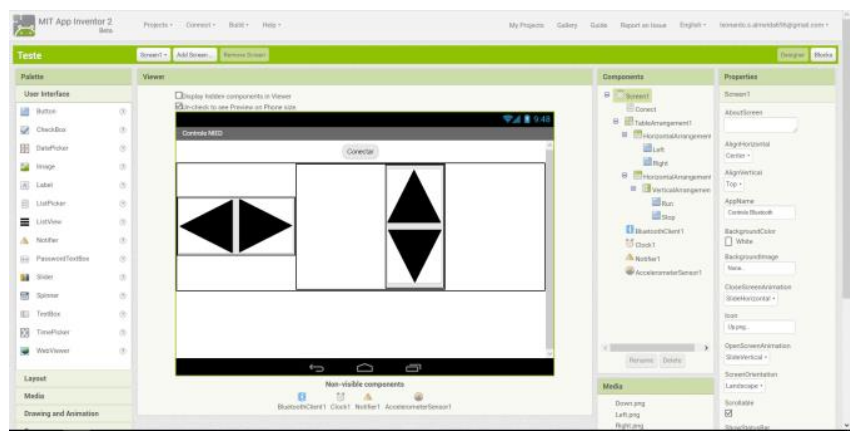

Image 1. IDE for programing of the app's screen.

The second tab is the real development environment, where we program the actions of the app (what will happen when the user touch in the determined area of the screen). An interesting point of this is the "language" chosen by MIT's researchers : Scratch[2]. This tab is shown in image 2.

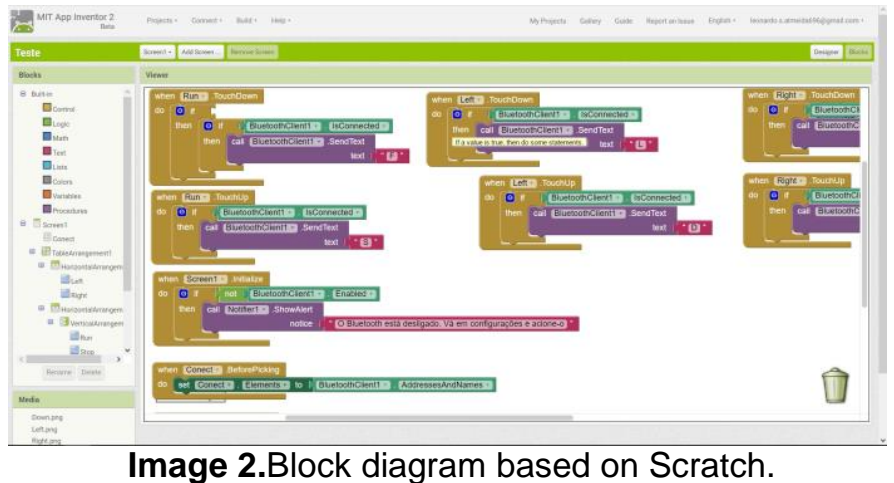

Our app, at this moment, is able to control a toy car through of the platform. It have some buttons: 1 to set up the comunication and 4 other to chose de direction of the car. How said, his screen is shown up in the image 1.

\section{Conclusions}

Creating this application we could have an experience in developing environment. Besides this, the atual version of our app met our expectation, enabling the control how we want (the app that we used before this, can't do whatever we wanted). Even so, we want improve our app using the Android Studio, software in which we can do so much more than in MIT App Inventor, but it's more complicated too.

\section{Acknowledgement}

We thanks to NIED, and to PRP-UNICAMP by the support and investment that made possible this research.

\footnotetext{
${ }^{1}$ MIT App Inventor. Avaible on: http://appinventor.mit.edu/

2 Scratch - Imagine, program, share. Avaible on: https://scratch.mit.edu/
} 